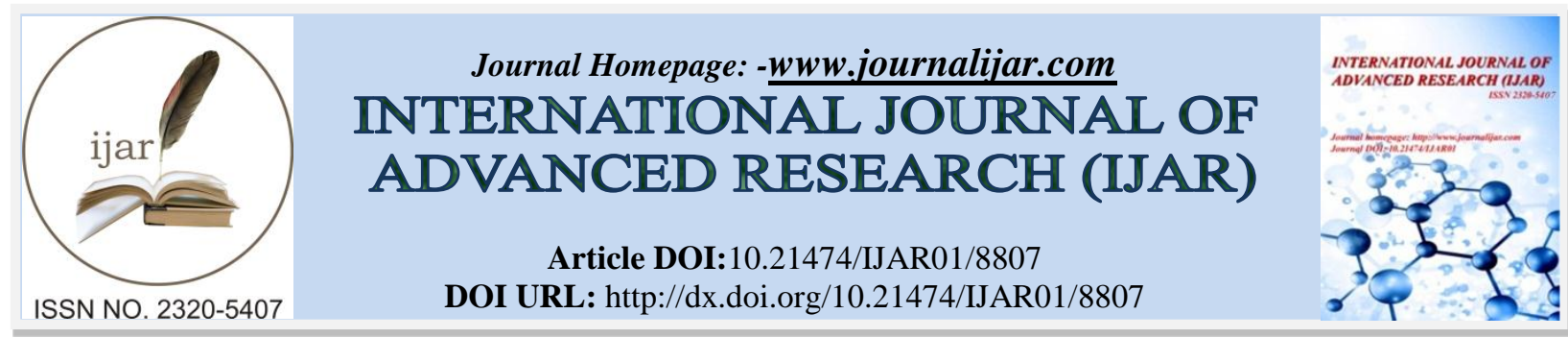

RESEARCH ARTICLE

\title{
PREDICTING FACTORS OF ORTHODONTIC PAIN - A SURVEY.
}

Nur Liyana Hannah Binti Izham Akmal ${ }^{1}$ and Dr. Saravana Pandian ${ }^{2}$.

1. Undergraduate Student Saveetha Dental College, Saveetha University, Chennai, India.

2. Reader Department of Orthodontics Saveetha Dental College, Saveetha Institute Of Medical And Technical Science, Saveetha University.

\section{Manuscript Info}

Manuscript History

Received: 04 February 2019

Final Accepted: 06 March 2019

Published: April 2019

Key words:-

Pain, patient, perception, discomfort, adaptation.

\section{Abstract}

Aim: To evaluate pain and discomfort experience by patients undergoing orthodontic treatment with different appliances after insertion and factors associated with orthodontic pain and to determine the factors associated with orthodontic pain and its effects on the quality of life of patients.

Background: Fear of pain during dental treatment is one of the major factors which prevent a patient from seeking orthodontic treatment. Pain and discomfort are commonly associated with orthodontic movement of teeth. Studies have shown that approximately $95 \%$ of orthodontic patients complained of pain during orthodontic treatment with $10 \%$ interrupting their treatment due to pain experienced during treatment. Pain is highly subjective as it may differ from one patient to another, in which some patients experience high levels of pain while others complain of just mild discomfort. It is very important for dentists to follow the progress of adaptation after insertion of new appliances and examine any pain or discomfort experienced by the patients.

Materials and Methods: A questionnaire-based study was done among dental students, practitioners and patients. A total of 100 participants took part in the survey. The participants were divided into 2 groups, Group 1 and 2. Group 1 consists of dental students and practitioners while Group 2 consists of dental patients. Each group was provided with a list of 10 questions related to pain during orthodontic treatment. Data was collected and statistic analysis was done.

Results: Moderate pain is most probably experienced by patients (62\%). Sensory perception of intensity and discomfort is considered as the main factor (52\%). Mold pain is commonly reported (44\%). Most cases begin within 24 hours (64\%) and usually subside within 24 hours (45\%). Pain sensitivity is commonly associated with orthodontic pain $(44 \%)$. Tests on anxiety level and dental fear is usually preferred $(52 \%)$. Patient's compliance remains good $(36 \%)$. NSAIDs is the best treatment of orthodontic pain (64\%). Patients are well-informed of the whole procedure $(82 \%)$.

8 is the moderate score of orthodontic pain (56\%). Patients experience pain within 2 to 3 days (72\%) with complains of moderate pain (94\%). Most patients are relaxed and calm before treatment $(78 \%)$ and some without negative experiences with dental procedure previously $(76 \%)$.

Corresponding Author:-Nur Liyana Hannah Binti Izham Akmal. 
Patients are aware of possible pain and discomfort (86\%). Some are prone to react to pain $(74 \%)$ although most are well informed of the whole procedure $(80 \%)$. Patients are still willing to proceed with the treatment despite having pain or discomfort.

Conclusion: Orthodontic pain has always been a great concern for most dentists all over the world. It is very important for every dentist to have a basic knowledge and understanding of orthodontic pain in order to overcome this condition in a clinical setting.

Copy Right, IJAR, 2019,. All rights reserved.

\section{Introduction:-}

Pain and discomfort are the two common conditions experienced by most orthodontic patients, which may occur up to a certain degree during a treatment procedure. Despite the recent advancement in orthodontics, most patients still experience some pain or discomfort associated with orthodontic treatment, especially 3 to 5 days after the placement of appliances. It has been reported that about $90 \%$ of patients complained of mild to severe acute pain at some stage during their orthodontic treatment. ${ }^{[1,2]}$

A report by the University of Mainz in Germany stated that patients normally begin to show adaptation to pain and discomfort with significant reduction in the number of complaints after 3 to 5 days following the placement of appliances. Patients rarely show further difference after the adaptation phase. ${ }^{[3]}$ The severity of pain and discomfort in these patients are much higher in those with functional or fixed appliances compared to patients with removable appliances. Some orthodontic patients may experience less pain and fast adaptation, while others may suffer great pain and slow adaptation, following a course of orthodontic treatment. Anxious patients and those with a history of chronic pain experience greater pain as compared to those with lower anticipation for pain after the treatment. ${ }^{\text {[4] }}$ Patients also complain of slurred speech, difficulty in swallowing and low self-confidence in public, mainly due to their appearance.

Various factors need to be considered in determining the main cause of orthodontic pain, which include the ability of patients to adapt after the insertion new appliances, type of appliances, degrees of pain and discomfort, patient's attitude towards the treatment and their effects on patient's compliance. ${ }^{[5]}$ The type of appliances may have significant effects on the patient's speech and swallowing, while patient's expectation of a good dental treatment and better appearance can lead to feeling of oral restriction and low self-confidence in public. Patient's experience with initial pain and discomfort can contribute to the acceptance of orthodontic treatment in general. Hence, this study aims to evaluate pain and discomfort experience by patients undergoing orthodontic treatment with different appliances after insertion and factors associated with orthodontic pain.

\section{Materials and Method:-}

A questionnaire-based study was done among 100 participants who took part in the survey. The participants were divided into Group 1 consisting of 50 dental students and practitioners and Group 2 with a total of 50 dental patients coming for orthodontic treatment. All the participants were provided with a list of 10 questions related to pain during orthodontic treatment. Each group was given with different sets of questions. Data was collected and statistic analysis was done. Ideally, the sample size of the survey was calculated to be 132, which indicates 100 participants are sufficient for this study. 


\section{Sample Size for Frequency in a Population}

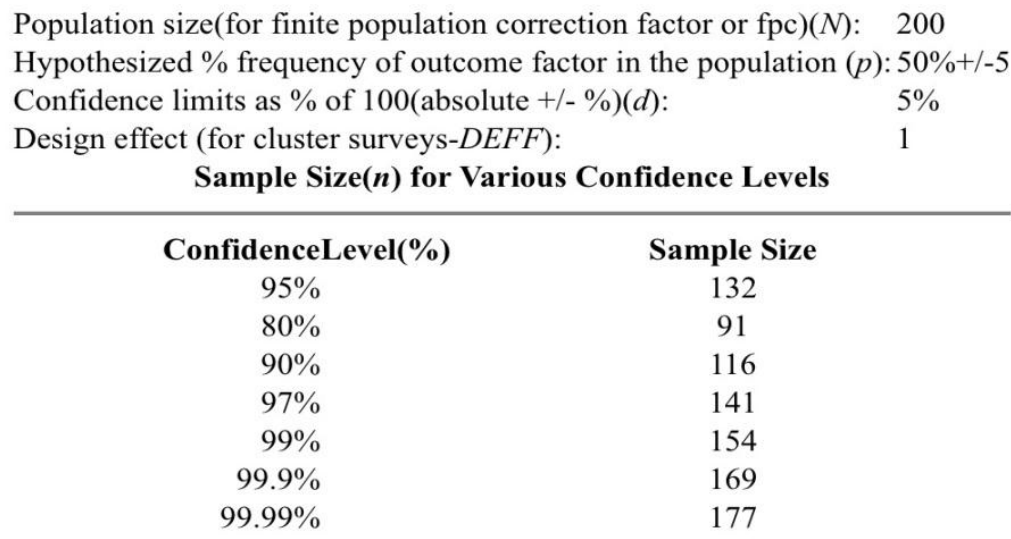

Equation
Sample size $n=[D E F F * N p(1-p)] /\left[\left(d^{2} / \mathbf{Z}^{2}{ }_{1-\alpha / 2}{ }^{*}(\mathbf{N}-\mathbf{1})+p^{*}(\mathbf{1}-\mathbf{p})\right]\right.$

Results from OpenEpi, Version 3, open source calculator--SSPropor Print from the browser with ctrl-P or select text to copy and paste to other programs.

Figure 1:-Sample size calculation ${ }^{[6]}$

Table 1 (a):-Survey questions on orthodontic pain along with answers (for dental students and practitioners)

\begin{tabular}{|c|c|}
\hline \multicolumn{2}{|r|}{ GROUP 1: DENTAL STUDENTS AND PRACTITIONERS } \\
\hline No. & Questions and Answers \\
\hline 1. & 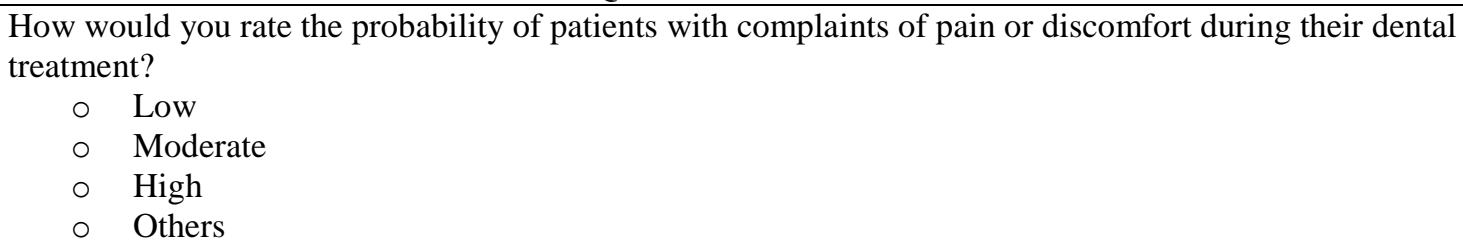 \\
\hline 2. & $\begin{array}{cl}\text { What do you think is the main component which contribute to orthodontic pain? } \\
\circ \text { Sensory perception of intensity and discomfort } \\
\circ \text { Cognitive influence } \\
\circ \quad \text { Emotional influence } \\
\circ & \text { Environmental influence } \\
\circ & \text { Psychological factors } \\
\circ & \text { Genetic factors or Personal traits } \\
\circ & \text { Others }\end{array}$ \\
\hline 3. & $\begin{array}{l}\text { How would you rate the severity of pain or discomfort experienced by your patients? } \\
\begin{array}{ll}\circ & \text { Mild } \\
\circ & \text { Moderate } \\
\circ & \text { Severe }\end{array}\end{array}$ \\
\hline 4. & $\begin{array}{ll}\text { When do your patients normally complain of pain or discomfort, following the placement of appliances? } \\
\circ \text { Within } 24 \text { hours } \\
\circ \quad \text { Within } 2 \text { to } 3 \text { days } \\
\circ & \text { Within } 4 \text { to } 5 \text { days } \\
\circ & \text { More than } 5 \text { days } \\
\circ & \text { Others }\end{array}$ \\
\hline & $\begin{array}{l}\text { When do the pain or discomfort experienced by your patients normally subside? } \\
\quad \text { Within } 24 \text { hours }\end{array}$ \\
\hline
\end{tabular}




\begin{tabular}{|c|c|c|}
\hline 5. & $\begin{array}{l} \\
0 \\
0 \\
0\end{array}$ & $\begin{array}{l}\text { Within } 2 \text { to } 3 \text { days } \\
\text { Within } 4 \text { to } 5 \text { days } \\
\text { More than } 5 \text { days } \\
\text { Others }\end{array}$ \\
\hline 6. & $\begin{array}{r}\text { Which } \\
0 \\
0 \\
0 \\
0 \\
0 \\
0 \\
0 \\
0\end{array}$ & $\begin{array}{l}\text { actor do you think is commonly associated with orthodontic pain? } \\
\text { Age } \\
\text { Gender } \\
\text { Ethnicity } \\
\text { Anxiety and Fear } \\
\text { Pain sensitivity } \\
\text { Mood } \\
\text { Catastrophizing } \\
\text { Others }\end{array}$ \\
\hline 7. & $\begin{array}{r}\text { How } \\
0 \\
0 \\
0 \\
0 \\
0 \\
0\end{array}$ & $\begin{array}{l}\text { uld you determine the risk of pain in your patients prior to an orthodontic treatment? } \\
\text { Cold pressor testing } \\
\text { Electric pulp testing } \\
\text { Self-rating on oral health } \\
\text { Tests on anxiety levels and dental fear } \\
\text { Genetic variation tests } \\
\text { Others }\end{array}$ \\
\hline 8. & $\begin{array}{r}\text { How } \\
0 \\
0 \\
0\end{array}$ & $\begin{array}{l}\text { uld you describe patient's compliance despite having pain or discomfort during the treatment? } \\
\text { Good } \\
\text { Moderate } \\
\text { Poor }\end{array}$ \\
\hline 9. & $\begin{array}{r}\text { Which } \\
0 \\
0 \\
0 \\
0 \\
\circ\end{array}$ & $\begin{array}{l}\text { nethod of pain control do you prefer for your patients? } \\
\text { Non-steroidal anti-inflammatory drugs (NSAIDs) } \\
\text { Low level laser therapy } \\
\text { Transcutaneous electrical neural stimulation } \\
\text { Vibratory stimulation } \\
\text { Others }\end{array}$ \\
\hline 10. & $\begin{array}{r}\text { Do yo } \\
\text { treatm } \\
0 \\
0 \\
0\end{array}$ & $\begin{array}{l}\text { normally ensure that your patients are well-informed of the whole procedure prior to the dental } \\
\text { t? } \\
\text { Yes } \\
\text { No } \\
\text { Sometimes }\end{array}$ \\
\hline
\end{tabular}

Table 1 (b):-Survey questions on orthodontic pain along with answers (for dental patients)

\begin{tabular}{|c|c|}
\hline \multicolumn{2}{|r|}{ GROUP 2: DENTAL PATIENTS } \\
\hline No. & Question and Answers \\
\hline 1. & $\begin{array}{l}\text { In the range of } 1 \text { to } 10 \text {, how would you rate the importance of seeking an orthodontic treatment? ( } 1 \text { being } \\
\text { the minimum and } 10 \text { being the maximum) } \\
\qquad 1 \text { (Minimum) }-10 \text { (Maximum) }\end{array}$ \\
\hline 2. & 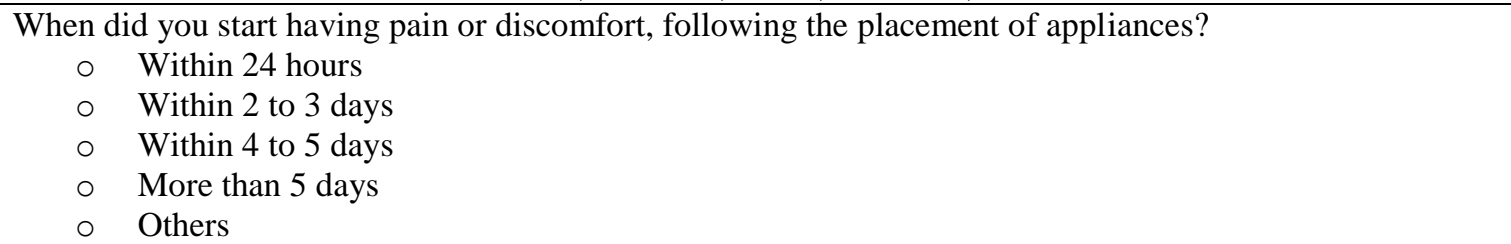 \\
\hline 3. & $\begin{array}{ll}\text { How long did it take for the pain or discomfort to subside? } \\
\therefore \text { Within } 24 \text { hours } \\
\circ \quad \text { Within } 2 \text { to } 3 \text { days } \\
\circ & \text { Within } 4 \text { to } 5 \text { days } \\
\circ & \text { More than } 5 \text { days } \\
\circ & \text { Others }\end{array}$ \\
\hline
\end{tabular}




\begin{tabular}{|c|c|}
\hline 4. & $\begin{array}{ll}\text { How would you rate the severity of pain you experienced during the treatment? } \\
\begin{array}{ll}\circ & \text { Mild } \\
\circ & \text { Moderate } \\
\circ & \text { Severe } \\
\circ & \text { None }\end{array}\end{array}$ \\
\hline 5. & $\begin{array}{l}\text { Have you ever had a negative experience with any dental treatment previously? } \\
\circ \text { Yes } \\
\circ \text { No }\end{array}$ \\
\hline 6. & $\begin{array}{ll}\text { How would you describe your condition prior to the treatment? } \\
\circ \text { Relaxed and calm } \\
\circ \text { Happy and excited } \\
\circ & \text { Anxious and worried } \\
\circ & \text { Others }\end{array}$ \\
\hline 7. & $\begin{array}{l}\text { Are you aware of the possible pain and discomfort associated with orthodontic treatment before you started } \\
\text { it? } \\
\qquad \text { Yes } \\
\circ \text { No }\end{array}$ \\
\hline 8. & $\begin{array}{l}\text { Are you generally prone to react with pain, even in situations other than dentistry? } \\
\begin{array}{ll}\circ & \text { Yes } \\
\circ & \text { No } \\
\circ & \text { Sometimes }\end{array}\end{array}$ \\
\hline 9. & $\begin{array}{l}\text { Do you think you are well-informed about the whole procedure prior to the dental treatment? } \\
\therefore \text { Yes } \\
\circ \quad \text { No } \\
\circ \text { Not sure }\end{array}$ \\
\hline 10. & $\begin{array}{l}\text { Are you still willing to proceed with the dental treatment despite having pain or discomfort? } \\
\circ \text { Yes } \\
\circ \text { No }\end{array}$ \\
\hline
\end{tabular}

\section{Results and Explanation}

Group 1: Dental Students and Practitioners

Table 2:-"How would you rate the probability of patients with complaints of pain or discomfort during their dental treatment?"

\begin{tabular}{|c|c|}
\hline Question 1 & Percentage of Individuals (\%) \\
\hline Low & 9 \\
\hline Moderate & 31 \\
\hline High & 10 \\
\hline Other & 0 \\
\hline
\end{tabular}




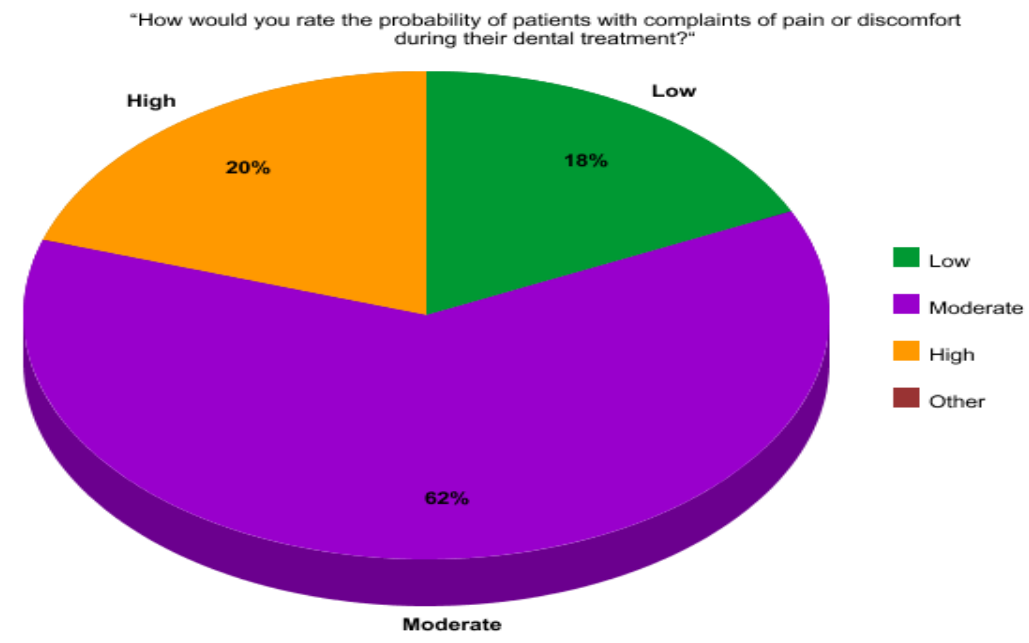

Figure 2:-"How would you rate the probability of patients with complaints of pain or discomfort during their dental treatment?"

Table 3:-"What do you think is the main component which contributes to orthodontic pain?"

\begin{tabular}{|c|c|}
\hline Question 2 & Percentage of Individuals (\%) \\
\hline Sensory perception of intensity and discomfort & 26 \\
\hline Cognitive influence & 3 \\
\hline Emotional influence & 8 \\
\hline Environmental influence & 2 \\
\hline Psychological factors & 10 \\
\hline Genetic factors or personal traits & 1 \\
\hline Other & 0 \\
\hline
\end{tabular}

"What do you think is the main component which contribute to orthodontic pain?"

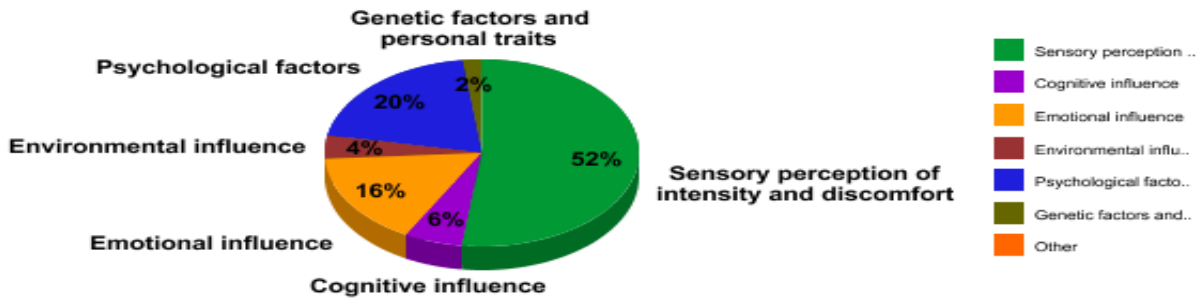

Figure 3:-"What do you think is the main component which contribute to orthodontic pain?"

Table 4:-"How would you rate the severity of pain or discomfort experienced by your patients?"

\begin{tabular}{|c|c|}
\hline Question 3 & Percentage of Individuals (\%) \\
\hline Mild & 22 \\
\hline Moderate & 21 \\
\hline Severe & 7 \\
\hline
\end{tabular}




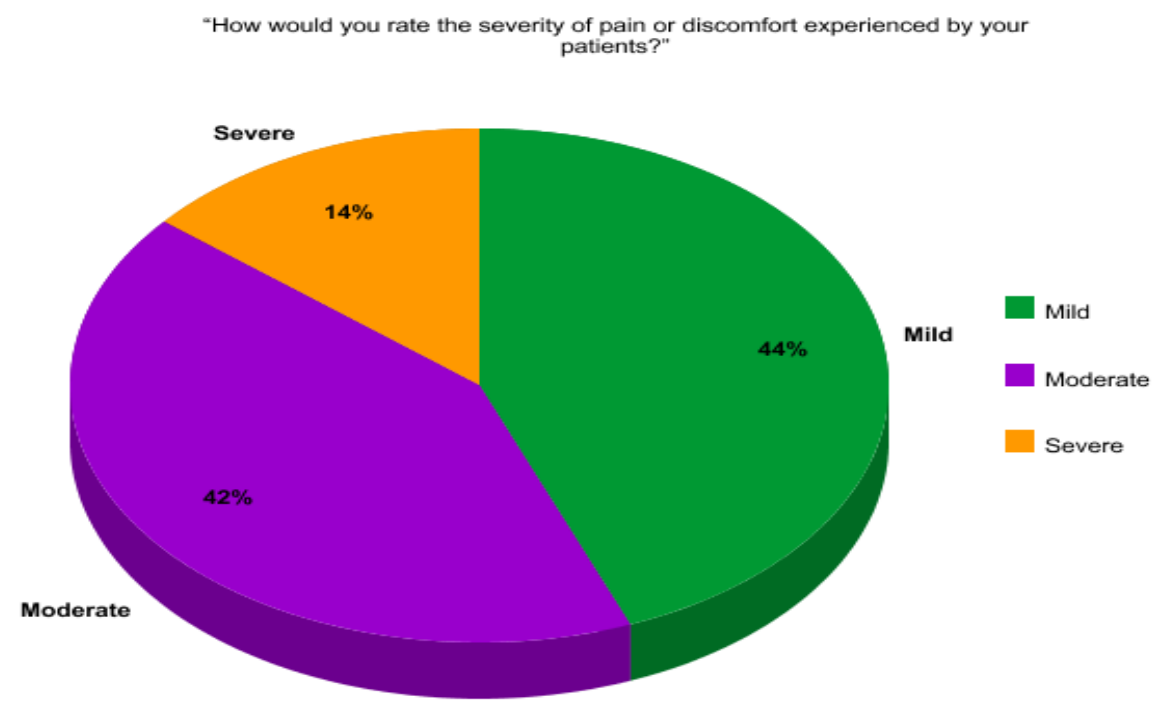

Figure 4:-"How would you rate the severity of pain or discomfort experienced by your patients?"

Table 5:-"When do your patients normally complain of pain or discomfort, following the placement of appliances?"

\begin{tabular}{|c|c|}
\hline Question 4 & Percentage of Individuals (\%) \\
\hline Within 24 hours & 32 \\
\hline Within 2 to 3 days & 10 \\
\hline Within 4 to 5 days & 6 \\
\hline More than 5 days & 2 \\
\hline Other & 0 \\
\hline
\end{tabular}

"When do your patients normally complain of pain or discomfort, following the placement of appliances?"

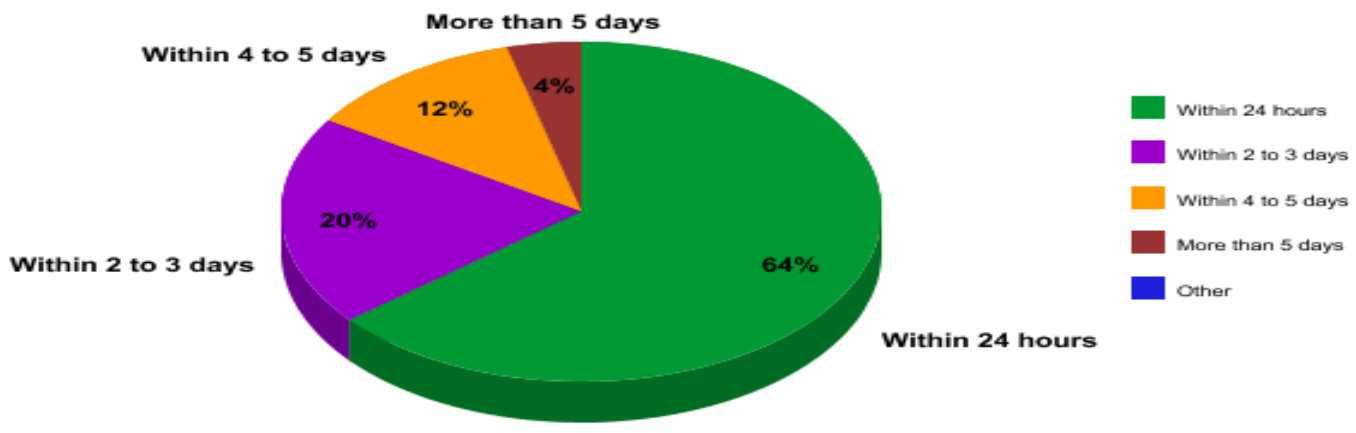

Figure 5:-"When do your patients normally complain of pain or discomfort, following the placement of appliances?"

Table 6:-"When do the pain or discomfort experienced by your patients normally subside?"

\begin{tabular}{|c|c|}
\hline Question 5 & Percentage of Individuals (\%) \\
\hline Within 24 hours & 27 \\
\hline Within 2 to 3 days & 13 \\
\hline Within 4 to 5 days & 3 \\
\hline
\end{tabular}




\begin{tabular}{|c|c|}
\hline More than 5 days & 7 \\
\hline Other & 0 \\
\hline
\end{tabular}

"When do the pain or discomfort experienced by your patients normally subside?"

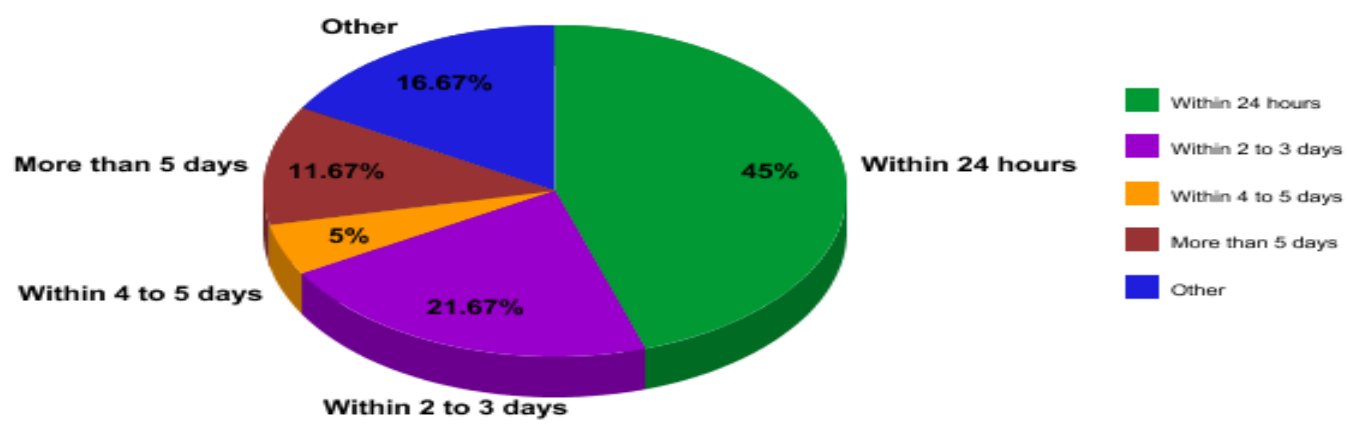

Figure 6:-“When do the pain or discomfort experienced by your patients normally subside?"

Table 7:-"Which factor do you think is commonly associated with orthodontic pain?"

\begin{tabular}{|c|c|}
\hline Question 6 & Percentage of Individuals (\%) \\
\hline Age & 3 \\
\hline Gender & 2 \\
\hline Ethnicity & 2 \\
\hline Anxiety and fear & 18 \\
\hline Pain sensitivity & 22 \\
\hline Mood & 1 \\
\hline Catastrophizing & 2 \\
\hline Other & 0 \\
\hline
\end{tabular}

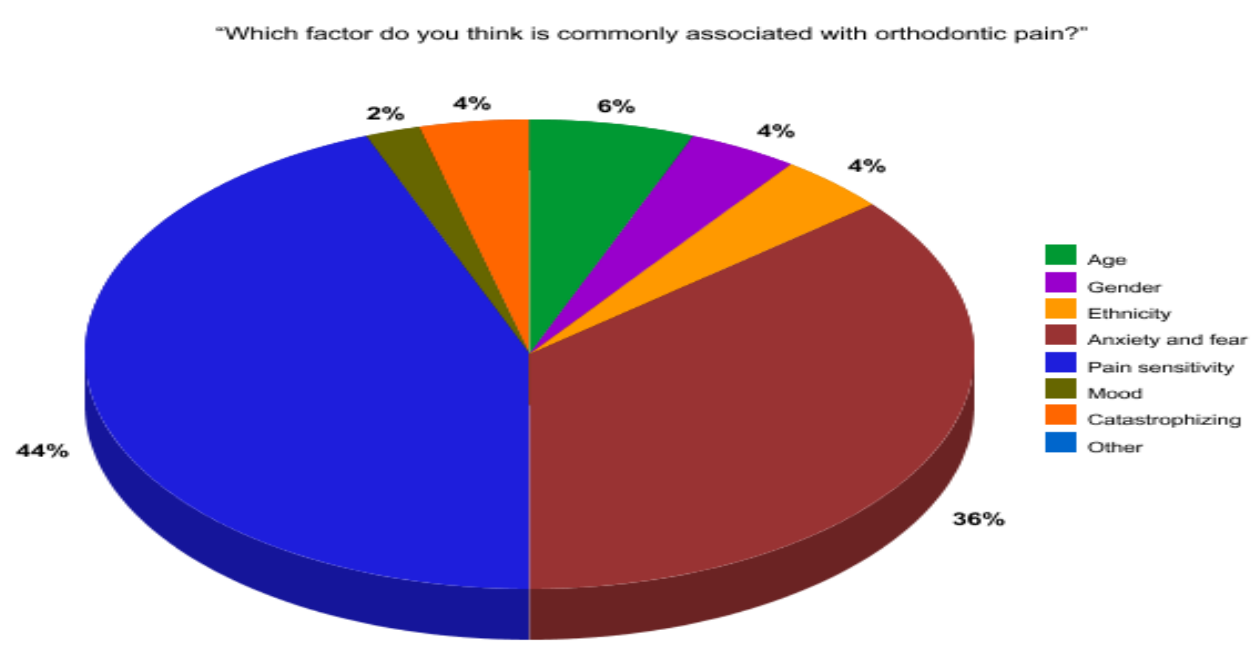

Figure 7:-“Which factor do you think is commonly associated with orthodontic pain?" 
Table 8:-"How would you determine the risk of pain in your patients prior to an orthodontic treatment?"

\begin{tabular}{|c|c|}
\hline Question 7 & Percentage of Individuals (\%) \\
\hline Cold pressure testing & 7 \\
\hline Electric pulp testing & 5 \\
\hline Self-rating on oral health & 11 \\
\hline Tests on anxiety levels and dental fear & 26 \\
\hline Genetic variation tests & 1 \\
\hline Other & 0 \\
\hline
\end{tabular}

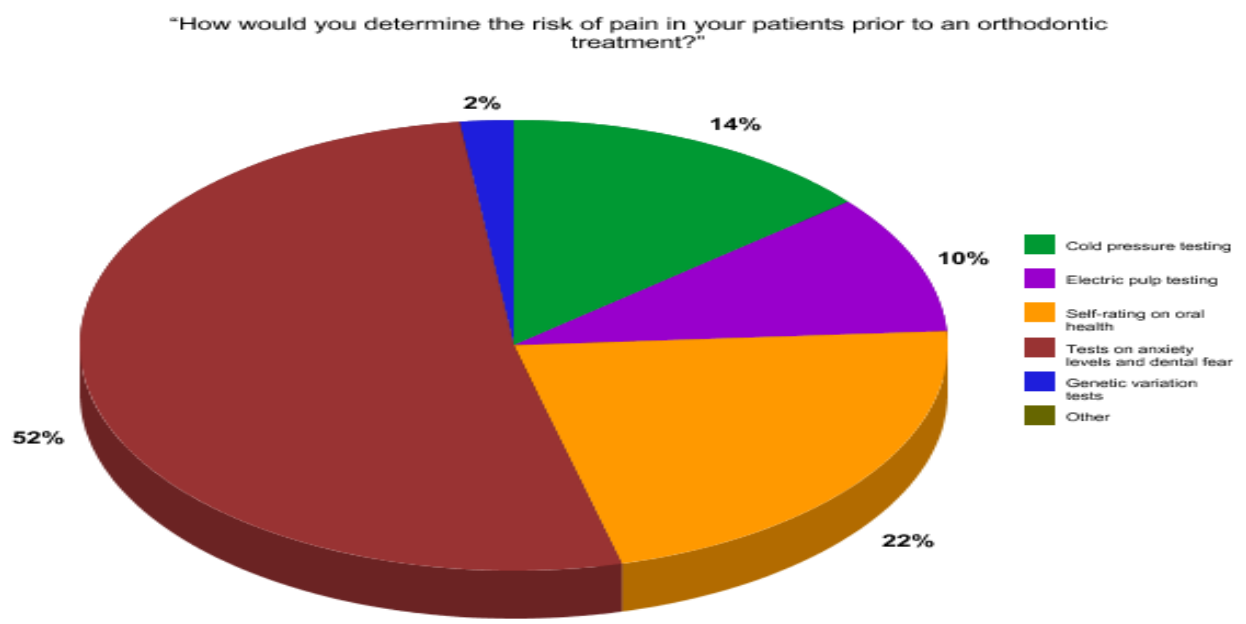

Figure 8:-"How would you determine the risk of pain in your patients prior to an orthodontic treatment?"

Table 9:-"How would you describe patient's compliance despite having pain or discomfort during the treatment?"

\begin{tabular}{|c|c|}
\hline Question 8 & Percentage of Individuals (\%) \\
\hline Good & 18 \\
\hline Moderate & 24 \\
\hline Poor & 8 \\
\hline
\end{tabular}

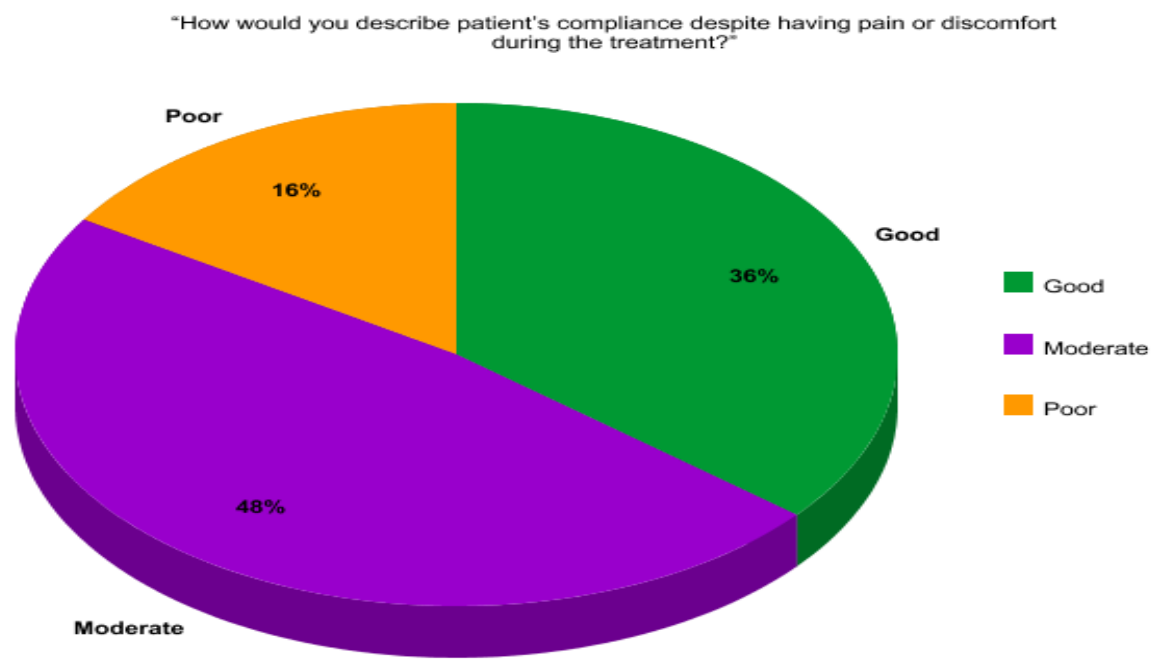

Figure 9:-"How would you describe patient's compliance despite having pain or discomfort during the treatment?" 
Table 10:-"Which method of pain control do you prefer for your patients?"

\begin{tabular}{|c|c|}
\hline Question 9 & Percentage of Individuals (\%) \\
\hline Non-steroidal anti-inflammatory drugs (NSAIDs) & 32 \\
\hline Low level laser therapy & 9 \\
\hline Transcutaneous electrical neural stimulation & 4 \\
\hline Vibratory stimulation & 5 \\
\hline Other & 0 \\
\hline
\end{tabular}

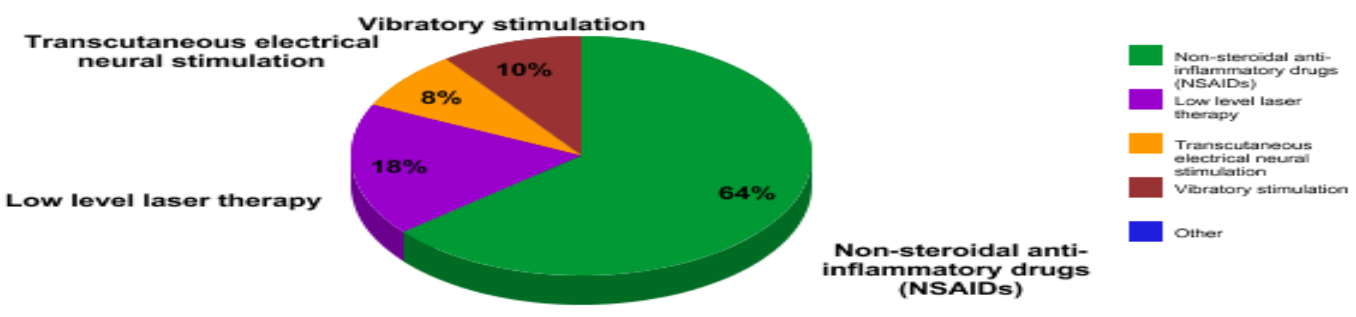

Figure 10:-"Which method of pain control do you prefer for your patients?"

Table 11:-"Do you normally ensure that your patients are well-informed of the whole procedure prior to the dental treatment?"

\begin{tabular}{|c|c|}
\hline Question 10 & Percentage of Individuals (\%) \\
\hline Yes & 41 \\
\hline No & 4 \\
\hline Sometimes & 5 \\
\hline Other & 0 \\
\hline
\end{tabular}

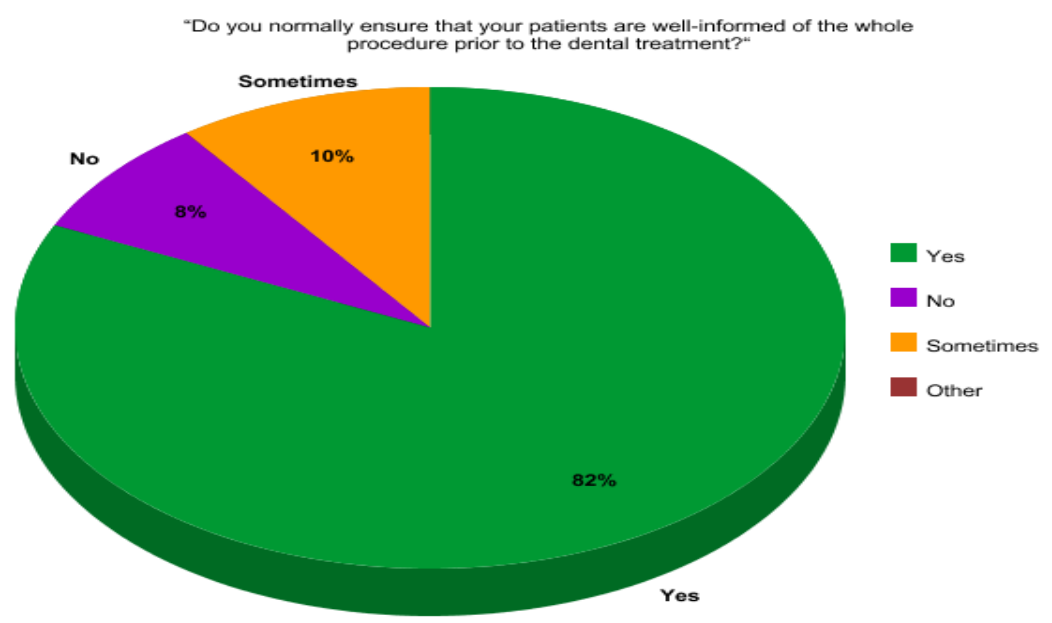

Figure 11:-“Do you normally ensure that your patients are well-informed of the whole procedure prior to the dental treatment?" 


\section{Group 2: Dental Patients}

Table 12:-"In the range of 1 to 10 , how would you rate the importance of seeking an orthodontic treatment? (1 being the minimum and 10 being the maximum)"

\begin{tabular}{|c|c|}
\hline Question 1 & Percentage of Participants (\%) \\
\hline 1 & 0 \\
\hline 2 & 0 \\
\hline 3 & 1 \\
\hline 4 & 0 \\
\hline 5 & 2 \\
\hline 6 & 1 \\
\hline 7 & 6 \\
\hline 8 & 28 \\
\hline 9 & 8 \\
\hline 10 & 8 \\
\hline
\end{tabular}

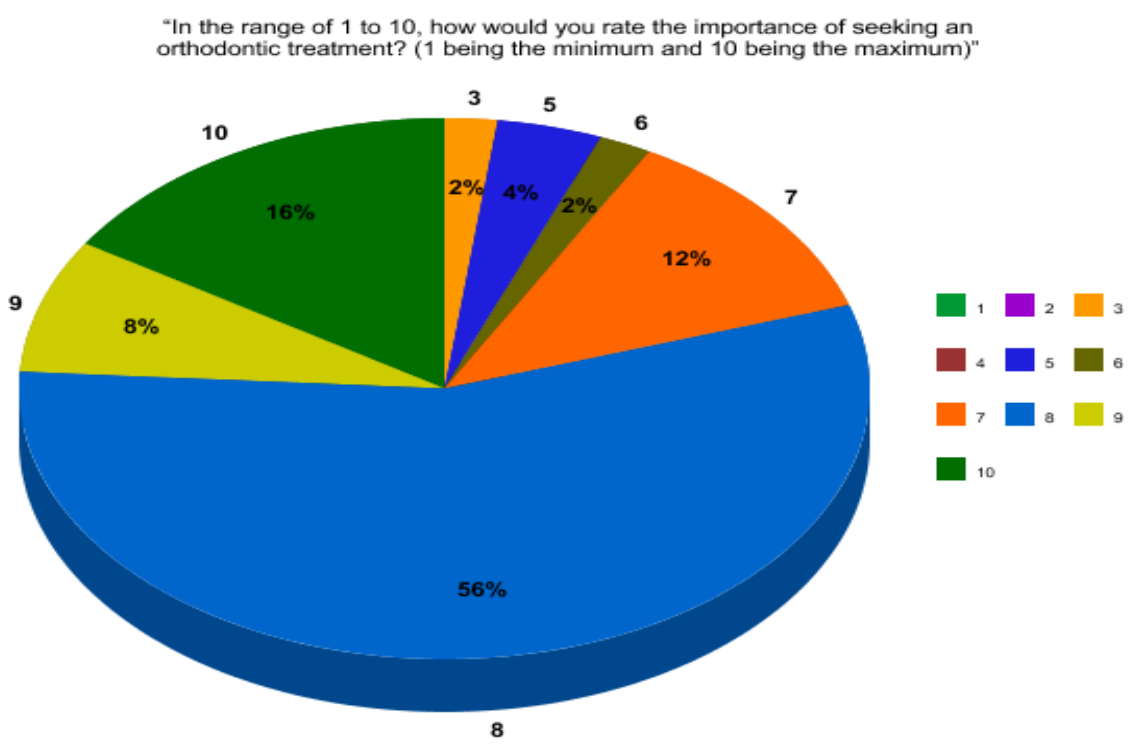

Figure 12:- "In the range of 1 to 10, how would you rate the importance of seeking an orthodontic treatment? (1 being the minimum and 10 being the maximum)"

Table 13:-"When did you start having pain or discomfort, following the placement of appliances?"

\begin{tabular}{|c|c|}
\hline Question 2 & Percentage of Individuals (\%) \\
\hline Within 24 hours & 9 \\
\hline Within 2 to 3 days & 36 \\
\hline Within 4 to 5 days & 1 \\
\hline More than 5 days & 4 \\
\hline Other & 0 \\
\hline
\end{tabular}




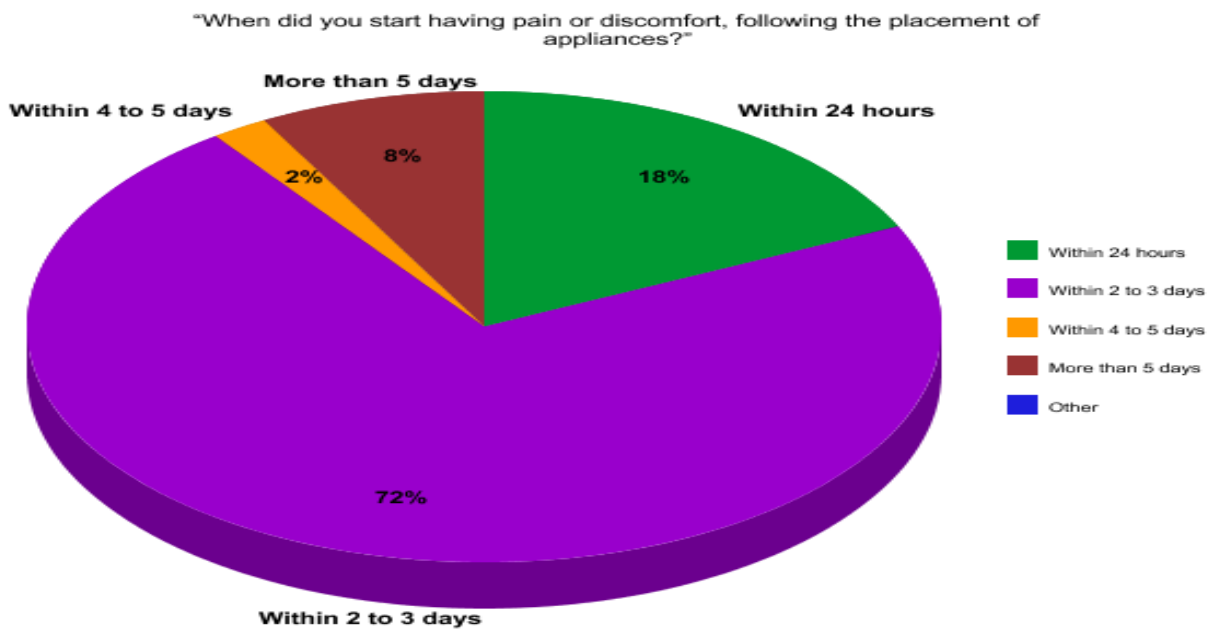

Figure 13:-"When did you start having pain or discomfort, following the placement of appliances?"

Table 14:-"How long did it take for the pain or discomfort to subside?"

\begin{tabular}{|c|c|}
\hline Question 3 & Percentage of Individuals (\%) \\
\hline Within 24 hours & 7 \\
\hline Within 2 to 3 days & 41 \\
\hline Within 4 to 5 days & 1 \\
\hline More than 5 days & 1 \\
\hline Other & 0 \\
\hline
\end{tabular}

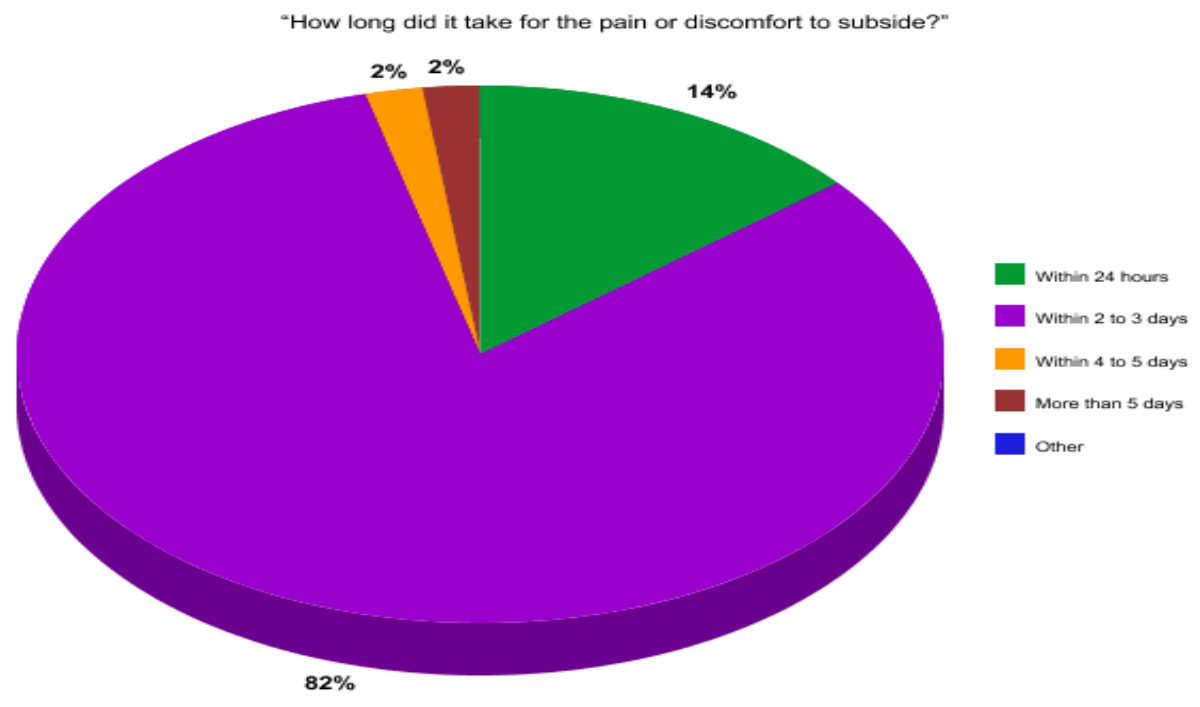

Figure 14:-"How long did it take for the pain or discomfort to subside?"

Table 15:-"How would you rate the severity of pain you experienced during the treatment?"

\begin{tabular}{|c|c|}
\hline Question 4 & Percentage of Individuals (\%) \\
\hline Mild & 2 \\
\hline Moderate & 47 \\
\hline Severe & 1 \\
\hline
\end{tabular}


"How would you rate the severity of pain you experienced during the treatment?"

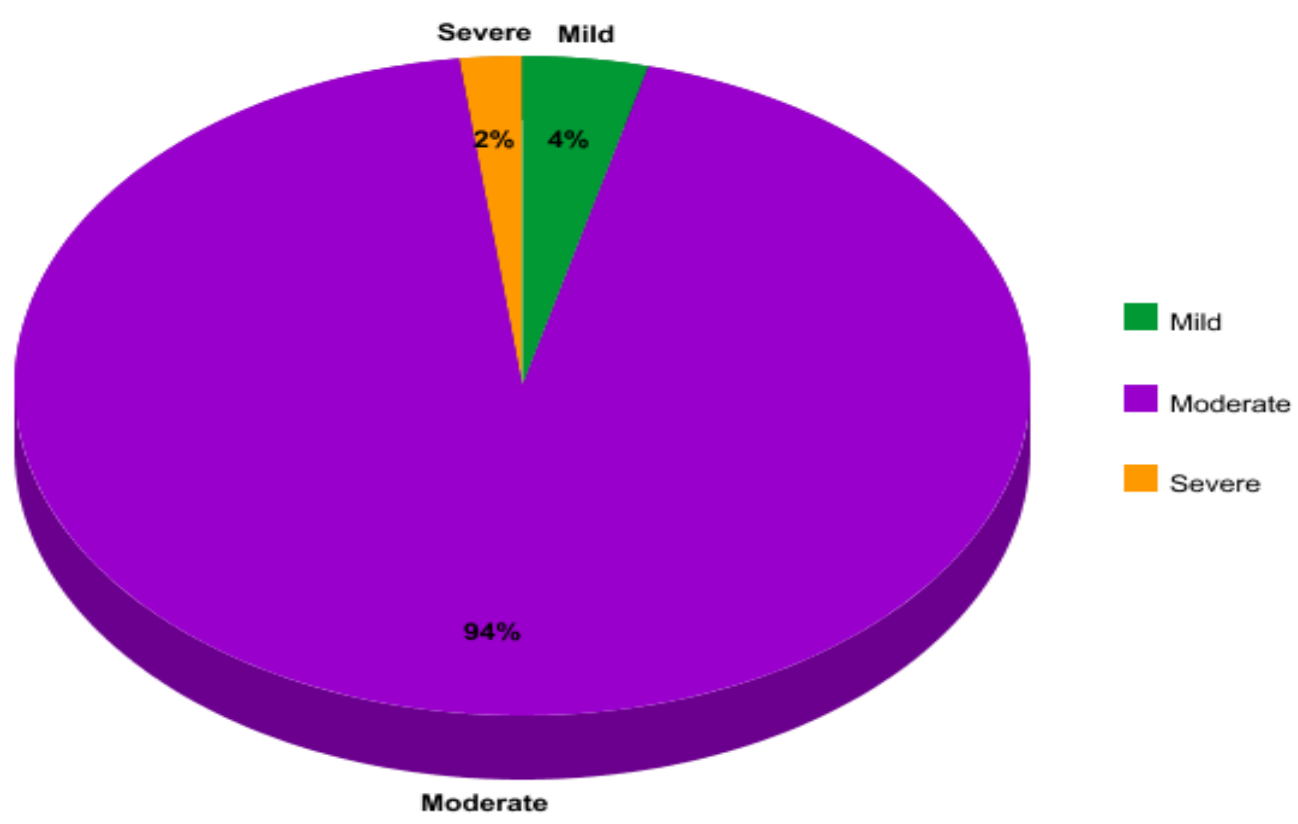

Figure 15:-"How would you rate the severity of pain you experienced during the treatment?"

Table 16:-"Have you ever had a negative experience with any dental treatment previously?"

\begin{tabular}{|c|c|}
\hline Question 5 & Percentage of Individuals (\%) \\
\hline Yes & 12 \\
\hline No & 38 \\
\hline
\end{tabular}

"Have you ever had a negative experience with any dental treatment previously?"

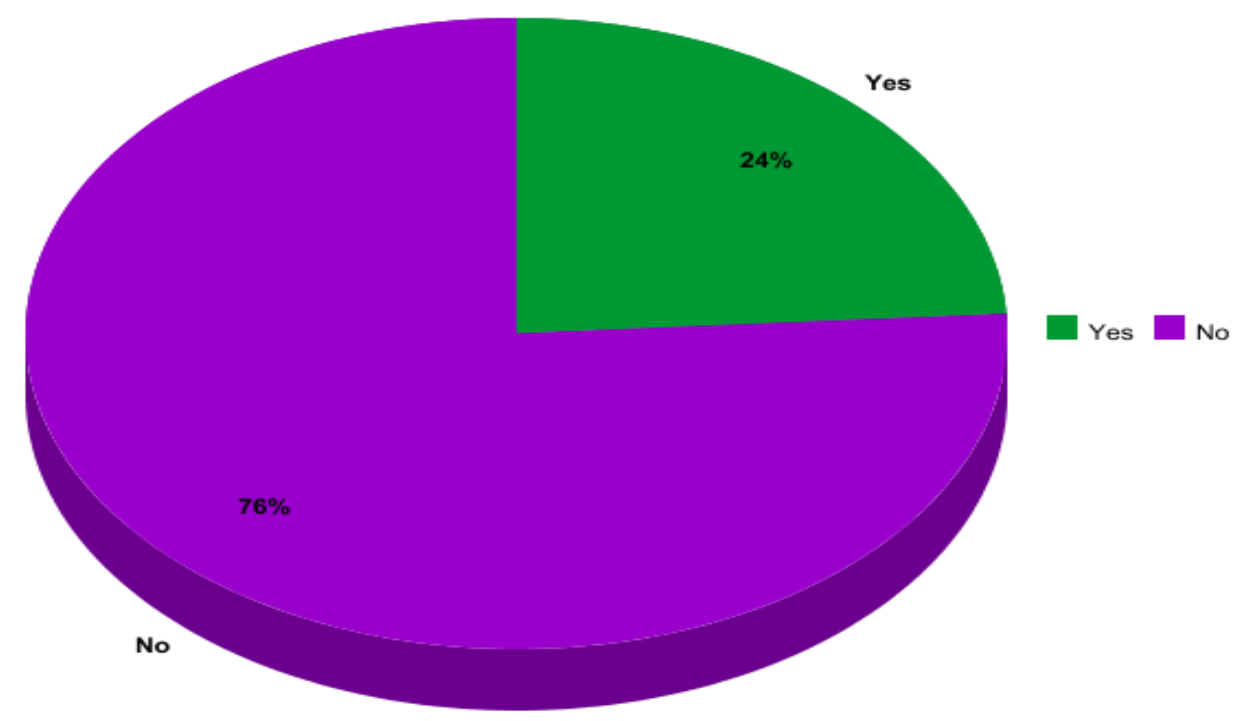

Figure 16:-"Have you ever had a negative experience with any dental treatment previously?" 
Table 17:-“How would you describe your condition prior to the treatment?"

\begin{tabular}{|c|c|}
\hline Question 6 & Percentage of Individuals (\%) \\
\hline Relaxed and calm & 39 \\
\hline Happy and excited & 0 \\
\hline Anxious and worried & 11 \\
\hline Other & 0 \\
\hline
\end{tabular}

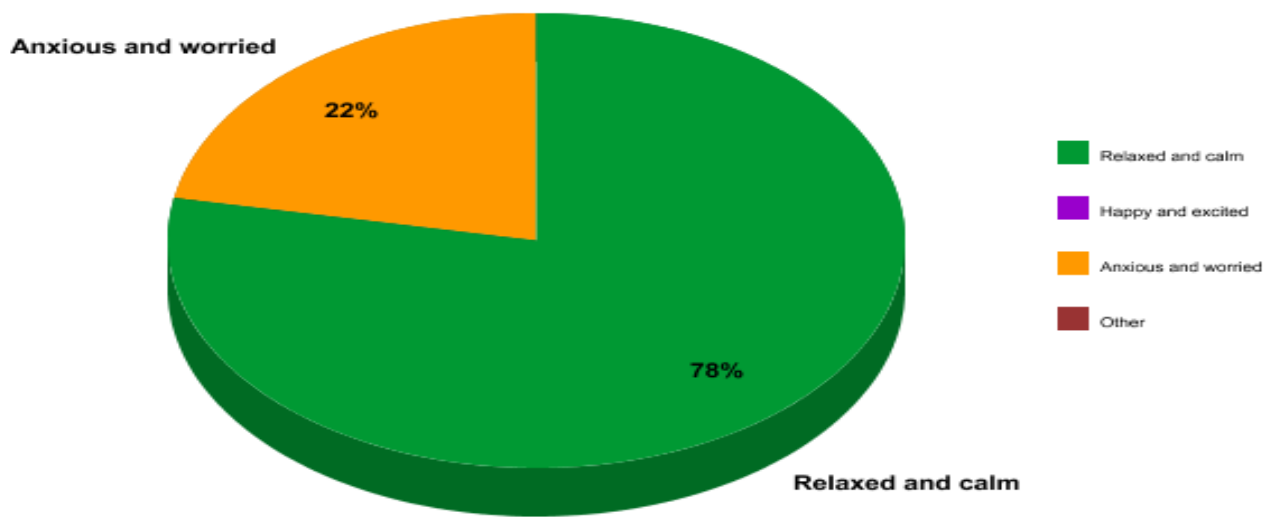

Figure 17:-"How would you describe your condition prior to the treatment?"

Table 18:-"Are you aware of the possible pain and discomfort associated with orthodontic treatment before you started it?"

\begin{tabular}{|c|c|}
\hline Question 7 & Percentage of Individuals (\%) \\
\hline Yes & 43 \\
\hline No & 7 \\
\hline
\end{tabular}

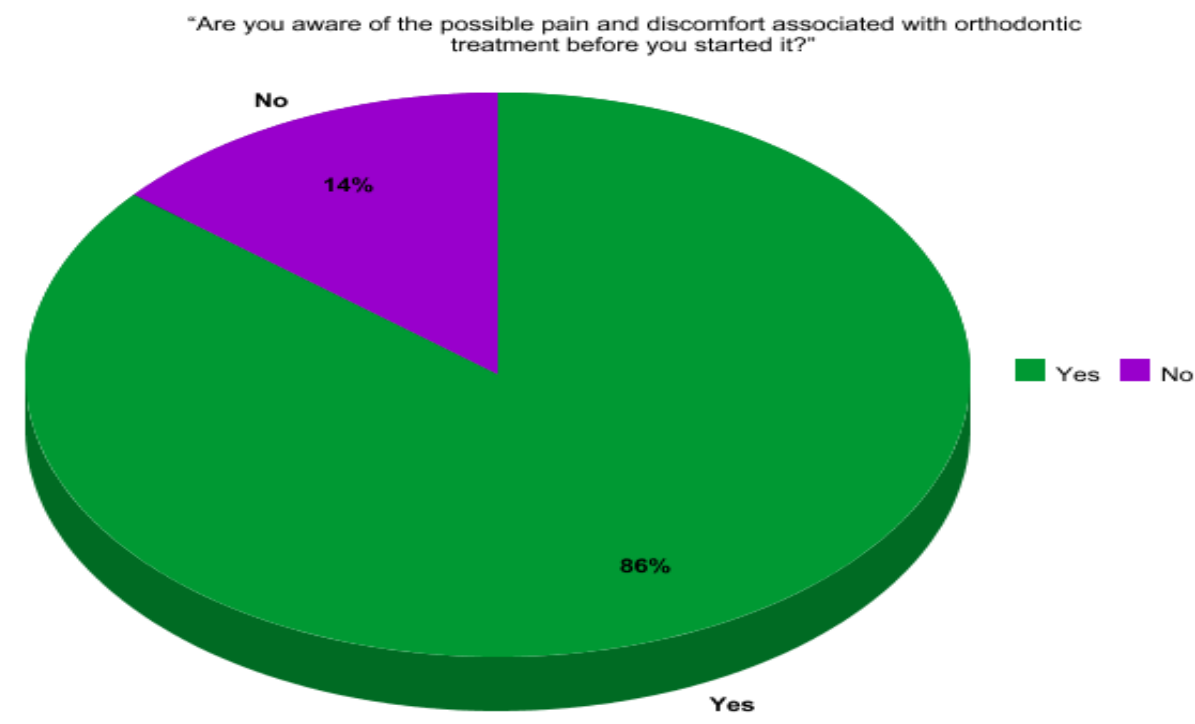

Figure 18:-"Are you aware of the possible pain and discomfort associated with orthodontic treatment before you started it?" 
Table 19:-“Are you generally prone to react with pain, even in situations other than dentistry?"

\begin{tabular}{|c|c|}
\hline Question 8 & Percentage of Individuals (\%) \\
\hline Yes & 37 \\
\hline No & 2 \\
\hline Sometimes & 11 \\
\hline
\end{tabular}

“Are you generally prone to react with pain, even in situations other than dentistry??

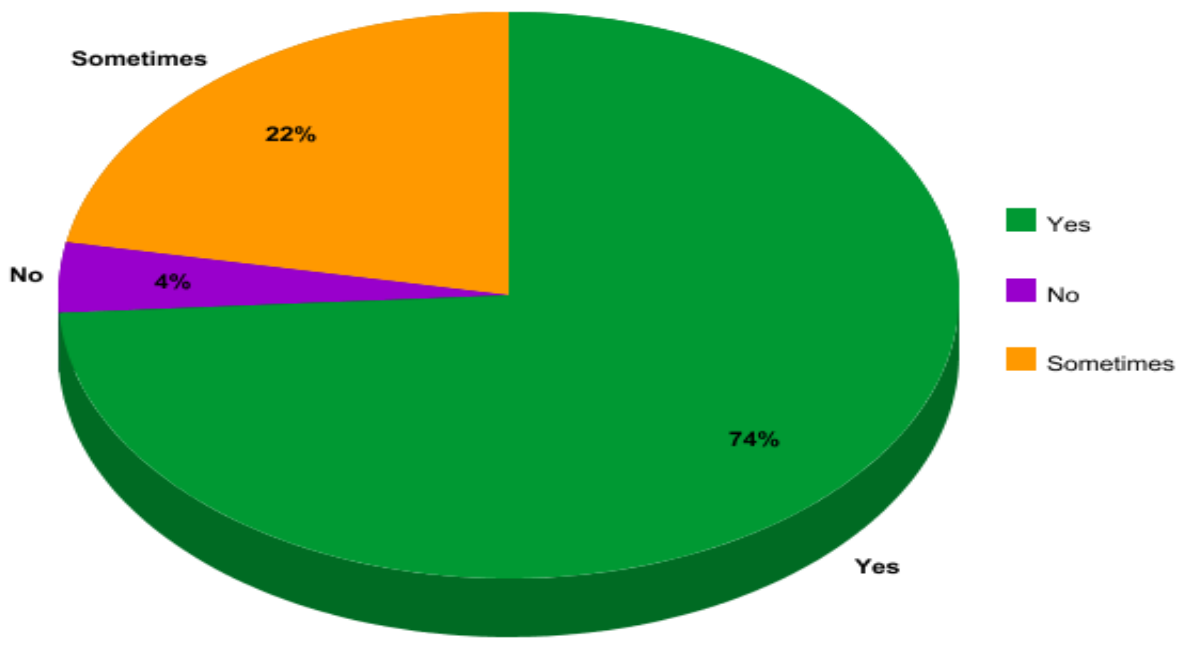

Figure 19:-“Are you generally prone to react with pain, even in situations other than dentistry?"

Table 20:-"Do you think you are well-informed about the whole procedure prior to the dental treatment?"

\begin{tabular}{|c|c|}
\hline Question 9 & Percentage of Individuals (\%) \\
\hline Yes & 40 \\
\hline No & 4 \\
\hline Not sure & 6 \\
\hline
\end{tabular}

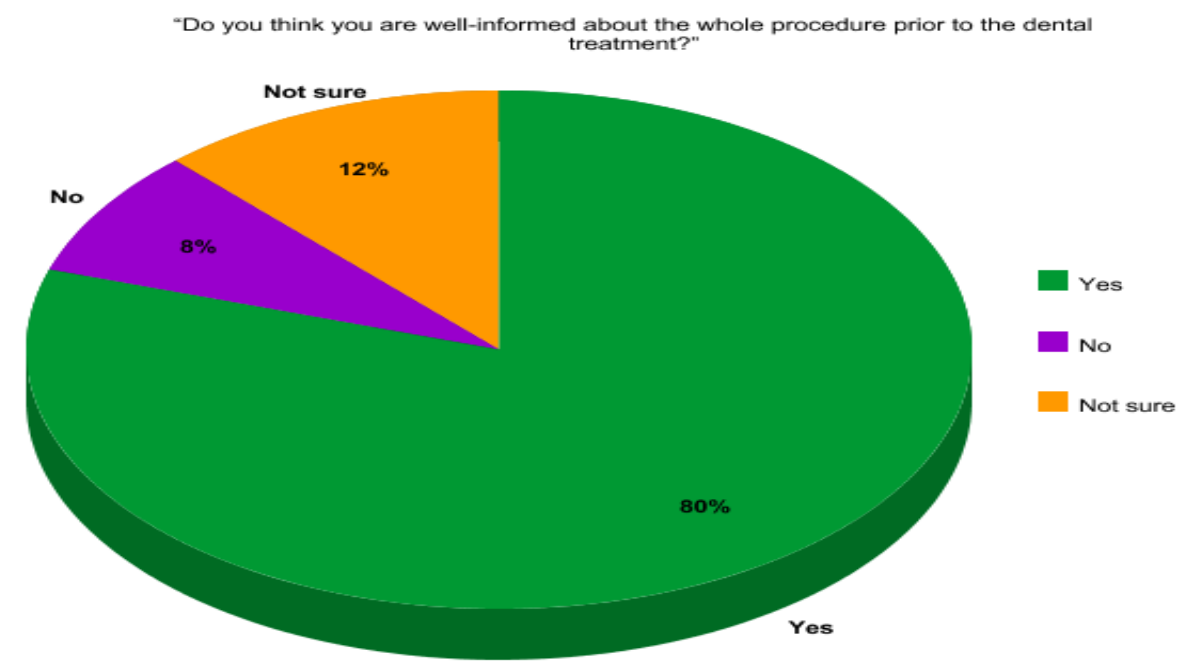

Figure 20:-"Do you think you are well-informed about the whole procedure prior to the dental treatment?" 
Table 21:-“Are you still willing to proceed with the dental treatment despite having pain or discomfort?"

\begin{tabular}{|c|c|}
\hline Question 10 & Percentage of Individuals (\%) \\
\hline Yes & 35 \\
\hline No & 15 \\
\hline
\end{tabular}

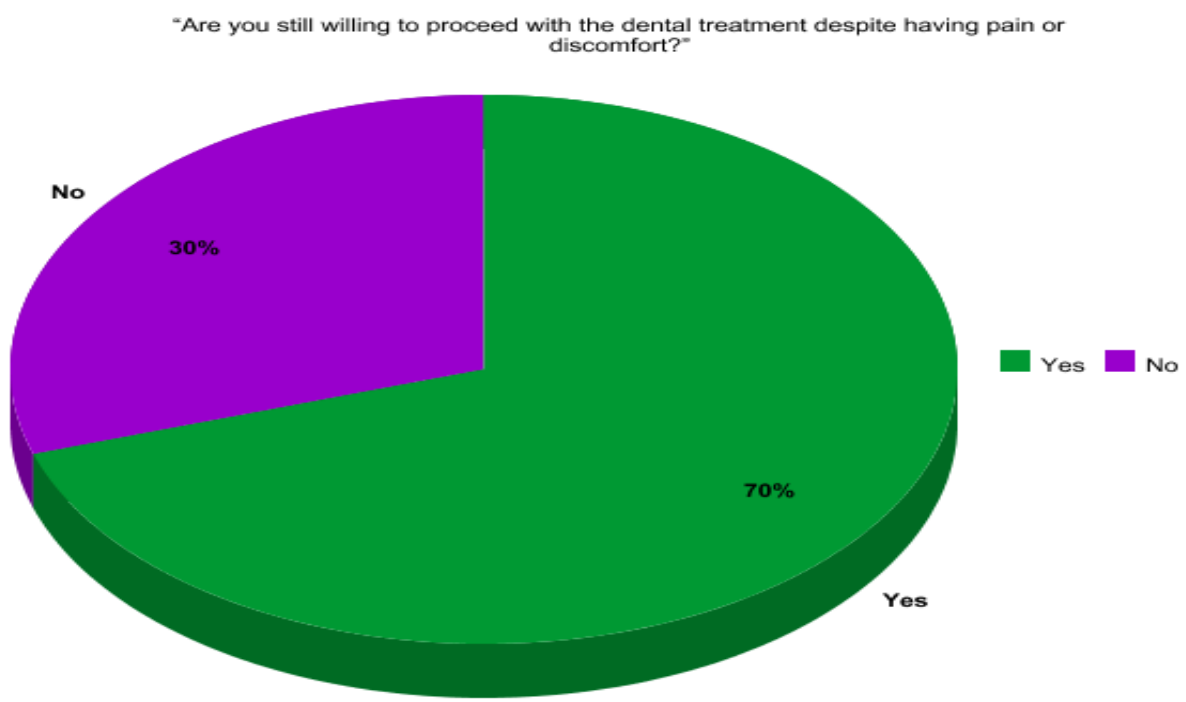

Figure 21:-“Are you still willing to proceed with the dental treatment despite having pain or discomfort?"

\section{Discussion:-}

\section{Group 1: Dental Students and Practitioners}

Based on Figure 1, 62\% of the participants had chosen "moderate" as the rate of probability of patients with complaints of pain and discomfort during their dental treatment. It can be seen that $20 \%$ of them have encountered many cases of orthodontic pain as they suggested that there is a "high" probability of such problem, while $18 \%$ of them disagree with the idea by stating that the probability of patients with orthodontic pain is low. A study done in Singapore involving 203 adult Chinese patients state that $91 \%$ of the patients reported of pain after the placement of orthodontic appliances with $31 \%$ of them complaining of pain during every step of the procedure. ${ }^{[1]}$

According to $52 \%$ of the participants, sensory perception of intensity and discomfort is the main component, which contributes to orthodontic pain while genetic factors or personal traits is the least associated with orthodontic pain as chosen by $2 \%$ of the participants. Psychological factors is considered as major factor of orthodontic pain by $20 \%$ of the participants, followed by $16 \%$ of them suggesting emotional influence as the principal component. The remaining factors of cognitive and environmental factors are chosen by $6 \%$ and $4 \%$ of the participants respectively. A report by Melzack R (1965) stated that orthodontic pain is commonly associated with sensory perceptions of intensity and discomfort, along with cognitive, emotional and environmental factors. ${ }^{[5,7,8]}$ The cognitive factors of pain often include patient's anticipation, memory of past experiences and attention. ${ }^{[5,9]}$ Various researches have been done to determine the correlation of orthodontic pain with psychological factors and personal traits, which requires substantial resources to obtain and evaluate the data from patients. ${ }^{[2,5,10]}$

$44 \%$ of the participants state that patients normally experience "mild" pain or discomfort in most cases of orthodontic pain, followed by $42 \%$ of them who rate the severity of pain as "moderate and only $14 \%$ of the total participants have seen patients with complaints of "severe" orthodontic pain. It has been reported that mild-to-severe pain can be seen in approximately $90 \%$ of patients seeking orthodontic treatment ${ }^{[1,2]}$

The result in Figure 4 suggests that most cases of orthodontic pain begin within 24 hours as stated by $64 \%$ of the participants. $20 \%$ of them indicate that orthodontic pain normally requires at least 2 to 3 days before it finally begins. While $12 \%$ of them suggest that it normally takes 4 to 5 days for patients to begin their complaints of orthodontic pain and the remaining $4 \%$ have had patients with orthodontic pain after 5 days of treatment. A report by Jones (1984) states that patients complain of maximum pain or discomfort begins within 24 hours after the placement of separators or arch wires. ${ }^{[11,12]}$ 
As for the relief of orthodontic pain, $45 \%$ of the participants state that it usually takes 24 hours for the pain to finally subsides, followed by approximately $22 \%$ of them indicating relief of orthodontic pain occurs within 2 to 3 days. $5 \%$ of the participants suggest that orthodontic pain may begin only after 4 to 5 days or it may require more than 5 days to subside as stated by about $12 \%$ of them. A study by Krishnan (2007) indicates that orthodontic pain generally subsides after 48 hours or approximately 2 to 3 days and further reduces to the pre-application state within 7 days. ${ }^{[3]}$ However, this idea is opposed by Scheurer et al who reported of pain in $25 \%$ of the patients even after 7 days. Another study states that pain normally disappears after 1 week, which supports the report by Jones (1984) who stated that the highest analgesic intake by most patients occurs within 3 days after the treatment. ${ }^{[2,12]}$

Pain sensitivity is the most selected factor to be commonly associated with orthodontic pain chosen by $44 \%$ of the participants, followed by anxiety and fear chosen by $36 \%$ of them in total. Age is also considered as a main factor of orthodontic pain by $6 \%$ of the participants. Gender, ethnicity and catastrophizing are the least common factors associated with orthodontic pain according to the participants, each with only $4 \%$ of the votes. A study by Schuerer in 1996 states that orthodontic pain is commonly associated with patients aged of 13 to 16 years old, but other studies disagree with this idea indicating that most cases of orthodontic pain are seen in older patients. ${ }^{[2,13]}$ When it comes to gender differences, it has been reported that females tend to have lower pain thresholds and more complaints of pain compared to males, which is believed to be due to their greater awareness towards external threats. ${ }^{[14]}$ In terms of ethnicity, A study by Woodrow and colleagues (1972) reported higher tolerance of pain in Caucasians compared to Asians who show higher tendency of pain and distress. It has been reported that anxiety and fear of dental treatment increases the tendency of orthodontic pain. ${ }^{[15]}$ A study by Stewart and King (1994) states that individual's psychological health is closely related to pain or discomfort through their health state. ${ }^{[16]}$ "Catastrophising" is a term used to describe "an individual's tendency to focus on and exaggerate the threat value of painful stimuli and negatively evaluate one's own ability to deal with pain". ${ }^{[17]}$ A study in Canada states that the tendency of pain increases in patients with excessive focus on their pain sensations. Another study indicates that more pain are seen in catastropisers than non-catastrophisers. ${ }^{[18]}$

Based on Figure 7, 52\% of the participants would conduct tests on anxiety levels and dental fear to access the tendency of orthodontic pain. $22 \%$ of them suggest self-rating on oral health as the best method to determine the risk of pain. $14 \%$ with cold pressure testing and $10 \%$ of them had chosen electric pulp testing. Only $2 \%$ of the total participants would consider genetic variation tests. In a previous study, it has been proven that cold pressor test provides a valid and low-risk test that can be used to examine pain and it has been widely used for research purposes. A study in Japan reported 99\% accuracy of EPT used in 396 teeth with vital pulps. ${ }^{[19]}$

Despite having orthodontic pain, patient's compliance is still good as indicated by $36 \%$ of the participants. As for $48 \%$ of the participants, patient's compliance becomes moderate following their experience with orthodontic pain while the remaining $16 \%$ indicates poor patient's compliance after their encounter with pain or discomfort. By comparison, a study by Patel in 1989 suggests that $10 \%$ of patients will discontinue their treatment due to their pain experience. It is supported by another study stating that every tenth orthodontic patient tend to stop attending their treatment due to the pain they experience during the early stages. ${ }^{[20,21]}$

In the treatment of orthodontic pain, $64 \%$ of the participants prefer the use of non-steroidal anti-inflammatory drugs (NSAIDs), followed by $18 \%$ with low level laser therapy, $8 \%$ with transcutaneous electrical neural stimulation and $10 \%$ chose vibratory stimulation as their preferred treatment modalities. According to Polat $\mathrm{O}$ and colleagues, NSAIDs is indeed the most preferred treatment modality for pain control with high rate of success. Unfortunately, many complications have been associated with the use of NSAIDs such as thrombocytopenia, skin rashes and headaches. ${ }^{[22]}$

In the matter of informing the patients of the whole procedure prior to the dental treatment, $82 \%$ answered "Yes", followed by $10 \%$ with "Sometimes" and "No" by $8 \%$ of the participants. From a previous study done by Johnson J and Leventhal $\mathrm{H}$, it can be seen that patients who are well-informed of the entire dental procedure required less pain medication than those who are unaware of the treatment process as patients are said to have average pain perception with proper knowledge about the procedure that they will undergo. ${ }^{[23]}$ This finding supports the study by Touyz and Marchand who indicate that the risk of pain reduces as the patient acquired better understanding of the complete procedure. $^{[24]}$ 


\section{Group 2: Dental Patients}

Based on Figure 1, it can be seen that most of the patients consider seeking an orthodontic treatment as important with an average score of $8.56 \%$ of the participants rated "8" as to how important an orthodontic treatment is for them and the minimum score of " 3 " is selected by $2 \%$ of the participants, which indicate their low desire for orthodontic treatment. It has been previously reported by Serg et al that patients with higher demand for orthodontic correction show lower intensity of pain as they are highly motivated to receive the treatment, while another study by Berguis et al indicates prolonged pain seen in less motivated patients. ${ }^{[25]}$

It can be seen that most patients normally experience pain or discomfort after 2 to 3 days of treatment as stated by $72 \%$ of them. Some may also experience pain within 24 hours as indicated by $18 \%$ of the participants, while $8 \%$ reported of pain only after 5 days or within 4 to 5 days as chosen by $2 \%$ of the participants. According to $82 \%$ of the participants, pain usually subside within 2 to 3 days after the treatment, while $14 \%$ of them suggest that the relief of orthodontic pain may occur within 24 hours. $2 \%$ of the participants indicate that pain relief only begins after 5 days or within 4 to 5 days as selected by another $2 \%$ of them.

In figure 4, most of the participants (94\%) complain of moderate pain, in which they experience during their orthodontic treatment. $4 \%$ of them have only experienced mild orthodontic pain and only $2 \%$ of the participants complained of severe pain during the treatment. It has been reported previously that patient's response to orthodontic treatment varies from one individual to another, as some patients may experience severe pain while others may complain of only slight discomfort. ${ }^{[7,26,27]}$

The result shown in Figure 5 states that $76 \%$ of the participants have never had a negative experience during any dental treatment before, while the remaining $24 \%$ of them showed otherwise as they have encountered such problem previously. It was reported that orthodontic pain is also commonly associated wit negative dental treatments, which may have been experienced by the patients previously. ${ }^{[28,29]}$ In a study by Locker D and colleagues, $71 \%$ of the patients reported that they have had a negative dental experience related to pain with $30 \%$ of them having more than 3 of such incidents. ${ }^{[30]}$

Based on Figure 6, it can be seen that most patients (78\%) attend the clinic while being relaxed and calm, although $11 \%$ of the participant showed the opposite, as they are often anxious and worried prior to a dental treatment. According to Keefe FJ and colleagues, affective states such as anxiety, fear, stress, panic and depression experienced by the patients prior to a dental treatment may contribute to pain perception and expression by the patients. ${ }^{[4]}$

Based on the patients' point of view, $86 \%$ of them are indeed aware of the possible pain and discomfort associated with orthodontic treatment before the procedure begins. On the contrary, $14 \%$ of the participants are unaware of this condition, which indicates their high expectation that the treatment is painless and comfortable throughout the time. A report by Bos et al states that patients who have had experiences of orthodontic treatment previously show better attitudes during the procedure as compared to those who have never experienced such treatment before. ${ }^{[33]}$

Generally, $74 \%$ of the patients are prone to react with pain, even in situations other than dentistry, $22 \%$ of them indicate such behavior only in some situations and the remaining $4 \%$ of them rarely react with pain in general settings.

The result in Figure 9 indicates that $80 \%$ of the participants agree that they are well-informed of the whole procedure prior to the start of treatment, $12 \%$ of them are unsure of whether they are aware of the entire procedure and $8 \%$ of the participants state that they are not informed properly of the procedure prior to the dental treatment.

Based on Figure 10, it can be seen that $70 \%$ of the participants are still willing to proceed with the dental treatment despite having pain or discomfort, while the remaining $15 \%$ of them would rather discontinue with the treatment. A study by Bergius $\mathrm{M}$ and colleagues reported that $70 \%$ of patients are willing to undergo prolonged duration of treatment, along with their readiness to experience severe pain in order to attain properly arranged teeth. ${ }^{[27]}$

\section{Conclusion:-}

Orthodontic pain has always been a great concern for most dentists all over the world. Pain is usually related an individual's personal experience which is rarely associated with injury to the tissue strtucture. Despite the current 
technology in orthodontics, most patients still experience some discomfort or pain in relation to orthodontic treatment with approximately $90 \%$ of patients would complain of pain during any stage of their dental treatment. Pain experienced by patient during an orthodontic treatment usually occurs along with other sensations such as anxiety and fear. ${ }^{32}$ It is very important for every dentist to have a basic knowledge and understanding of orthodontic pain in order to overcome this condition in a clinical setting.

\section{References:-}

1. Lew KK. Attitudes and perceptions of adults towards orthodontic treatment in an Asian community. Community Dentistry and Oral Epidemiology. 1993;21(1):31-5.

2. Scheurer PA, Firestone AR, Burgin WB. Perception of pain as a result of orthodontic treatment with fixed appliances. Eur J Orthod. 1996; 18(4):349-357.

3. Krishnan V. Orthodontic pain: from causes to management--a review. The European Journal of Orthodontics. 2007Nov;29(2):170-9.

4. Keefe FJ, Lumley M, Anderson T, Lynch T, Studts JL, Carson KL. Pain and emotion: new research directions. J Clin Psychol. 2001;57(4):587-607.

5. Yao L, Lin F, Ren M, Zheng B. Prediction of pain in orthodontic patients based on preoperative pain assessment. Patient Preference and Adherence. 2016;:251

6. Figure 1 from: Irimia R, Gottschling M (2016) Taxonomic revision of Rochefortia Sw. (Ehretiaceae, Boraginales). Biodiversity Data Journal 4: e7720.

7. Melzack R, Wall PD. Pain mechanisms: A new theory. Pain Forum. 1996;5(1):3-11.

8. Bergius M,Kiliaridis S,Berggren U.Pain in orthodontics.A review and discussion of the literature. J Orofac Orthop. 2000;61(2):125-137.

9. Peyron R, García-Larrea L, Grégoire M-C, Costes N, Convers P, Lavenne F, et al. Haemodynamic brain responses to acute pain in humans. Brain. 1999;122(9):1765-80.

10. Bergius $\mathrm{M}$, Broberg AG, Hakeberg $\mathrm{M}$, Berggren U. Prediction of prolonged pain experiences during orthodontic treatment. American Journal of Orthodontics and Dentofacial Orthopedics. 2008;133(3).

11. Ngan P, Kess B, Wilson S. Perception of discomfort by patients undergoing orthodontic treatment. American Journal of Orthodontics and Dentofacial Orthopedics. 1989;96(1):47-53.

12. Jones ML. An investigation into the initial discomfort caused by placement of an archwire. The European Journal of Orthodontics. 1984Jan;6(1):48-54.

13. Jones $\mathrm{M}$, Chan $\mathrm{C}$. The pain and discomfort experienced during orthodntic treatment: A randomized controlled clinical trial of two intial aligning arch wires. American Journal of Orthodontics and Dentofacial Orthopedics. 1992;102(4):373-81.

14. Diatchenko L, Slade GD, Nackley AG, Bhalang K, Sigurdsson A, Belfer I, et al. Genetic basis for individual variations in pain perception and the development of a chronic pain condition. Human Molecular Genetics. 2004Oct;14(1):135-43.

15. Woodrow KM, Friedman GD, Siegelaub AB, Collen MF (1972). Pain tolerance: differences according to age, sex and race. Psychosom Med 34(6):548-556.

16. Johansson S. Conceptualizing and Measuring Quality of Life for National Policy. Social Indicators Research Series Assessing Quality of Life and Living Conditions to Guide National Policy. New York, USA. Springer Publishing Co xvii:13-32.

17. Rosenstiel AK, Keefe FJ. The use of coping strategies in chronic low back pain patients: Relationship to patient characteristics and current adjustment. Pain. 1983;17(1):33-44.

18. Sullivan MJ, Stanish W, Sullivan ME, Tripp D. Differential Predictors of Pain and Disability in Patients with Whiplash Injuries. Pain Research and Management. 2002;7(2):68-74.

19. (19) Kitamura T, Takahashi T, Horiuchi H (1983). Electrical characteristics and clinical application of a new automatic pulp tester. Quintessence Int 1:45-53.

20. Patel V (1989). Non-completion of orthodontic treatment: a study of patient and parental factors contributing to discontinuation in the hospital service and specialist practice. Thesis, University of Wales, Heath Park, UK.

21. Beck VJ, Farella M, Chandler NP, Kieser JA, Thomson WM. Factors associated with pain induced by orthodontic separators. Journal of Oral Rehabilitation. 2014Jan;41(4):282-8.

22. Polat O, Karaman AI, Durmus E. Effects of preoperative ibuprofen and naproxen sodium on orthodontic pain. Angle Orthod. 2005; 75(5):791-796.

23. Johnson JE, Leventhal $\mathrm{H}$. Effects of accurate expectations and behavioral instructions on reactions during a noxious medical examination. Journal of Personality and Social Psychology. 1974;29(5):710-8. 
24. Touyz LZ, Marchand S. The influence of postoperative telephone calls on pain perception: a study of 118 periodontal surgical procedures. J Orofac Pain. 1998;12: 219-225.

25. Bergius $M$, Broberg AG, Hakeberg $M$, Berggren U. Prediction of prolonged pain experiences during orthodontic treatment. American Journal of Orthodontics and Dentofacial Orthopedics. 2008;133(3).

26. Ngan P, Kess B, Wilson S. Perception of discomfort by patients undergoing orthodontic treatment. American Journal of Orthodontics and Dentofacial Orthopedics. 1989;96(1):47-53.

27. Bergius M, Kiliaridis S, Berggren U (2000). Pain in orthodontics. A review and discussion of the literature. J Orofac Orthop 61(2):125-137.

28. Berggren U, Meynert G. Dental fear and avoidance: causes, symptoms, and consequences. J Am Dent Assoc 1984; 109: 247-251.

29. Williams JM, Murray JJ, Lund CA, Harkiss B, De Franco A. Anxiety in the child dental clinic. J Child Psychol Psychiatry 1985; 26: 305-310.

30. Locker D, Shapiro D, Liddel A. Negative dental experiences and their relationship to dental anxiety. Community Dent Health 1996;13:86-92.

31. Bos A, Hoogstraten J, Prahl-Andersen B. Attitudes towards orthodontic treatment: a comparison of treated and untreat- ed subjects. Eur J Orthod. 2005;27:148-154.

32. JP, Bell WE (2005). Bell's orofacial pains : the clinical management of orofacial pain. 6th ed. Chicago: Quintessence Pub. Co (pages 9-11, 13-41, 45-60, 87-89, 96, 97).

33. Muller E, Calvo M (2001). Pain and Dental Implantology: Sensory Quantification and Affective Aspects.: Part I: At the Private Dental Office. Implant Dent 10(1):14-22. 